\title{
A ARGUMENTAÇÃO COMO PRÁTICA DISCURSIVA: POR UMA ABORDAGEM LATO SENSU NO ENSINO BÁSICO
}

Alcione Tereza Corbari $^{1}$

\section{RESUMO}

Este artigo visa a refletir sobre a abordagem da argumentação no ensino básico, focando livros didáticos voltados ensinos Fundamental e Médio. Sem desconsiderar a importância da argumentação stricto sensu como conteúdo de ensino da disciplina de Língua Portuguesa, este texto argumenta sobre a necessidade de garantir a noção lato sensu de argumentação como tópico curricular básico dessa disciplina. Essa proposta fundamenta-se na teoria ducrotiana da argumentatividade inscrita na língua e considera que a interação pela linguagem constitui um ato social que é, em essência, argumentativo, o que significa compreender a argumentação como prática social e discursiva intrínseca ao uso da língua, portanto, não restrita a contextos específicos de interação.

Palavras-chave: Argumentação. Língua Portuguesa. Ensino Básico.

\section{ARGUMENTATION AS DISCURSIVE PRACTICE: FOR A LATO SENSU APPROACH IN BASIC EDUCATION}

\section{ABSTRACT}

This article aims to present some reflections on teaching argumentation in basic education, considering the treatment of this theme in Elementary and Secondary textbooks. Despite the importance of argumentation in stricto sensu as content in Portuguese Language teaching, this text argues that the argumentation in lato sensu must figure as a basic curricular topic of

1 Doutora em Letras e Linguística pela Universidade Federal da Bahia. Professora dos Cursos de Graduação e Pós-Graduação da Unioeste, campus de Cascavel. ORCID:orcid.org/0000-0002-3247-7191. E-mail alcione_corbari@hotmail.com 
this discipline. This proposal is based on the Theory of Argumentation within Language and considering that the interaction by language constitutes a social act that is essentially argumentative, which means to comprehend argumentation as social and discursive practice intrinsic to the language uses, not restricted to specific interaction contexts.

Keywords: Argumentation. Portuguese Language subject. Basic Education.

\section{ARGUMENTACIÓN COMO PRÁCTICA DISCURSIVA: PARA UN ENFOQUE LATO SENSU EN EDUCACIÓN BÁSICA}

\section{RESUMEN}

El propósito de este artículo es presentar algunas reflexiones sobre la enseñanza de la argumentación en la educación básica, centrando-se en libros de texto de la escuela primaria y secundaria. A pesar de la importancia de la argumentación en stricto sensu como contenido en la enseñanza de la lengua portuguesa, este texto argumenta que la argumentación en lato sensu debe figurar como un tema curricular básico de esta disciplina. Esta propuesta se basa en la teoría de la argumentación dentro del lenguaje y considera que la interacción por el lenguaje constituye un acto social esencialmente argumentativo, lo que significa comprender la argumentación como práctica social y discursiva intrínseca a los usos del lenguaje, no restringida a contextos de interacción específicos.

Palabras clave: Argumentación. Lengua portuguesa. Educación Básica.

\section{INTRODUÇÃO}

A argumentação é tópico de estudo de diferentes áreas, como a Linguística, a Filosofia e a Lógica, por exemplo. Quando focamos a grande área da Linguística, que é o campo que nos interessa aqui, observamos diferentes abordagens desse assunto segundo as 
orientações teóricas de cada subárea, como a Retórica, a Análise do Discurso, a Análise da Conversação, a Pragmática ou a Semântica, por exemplo. E, mesmo restringindo o olhar para uma dessas vertentes, ainda é preciso considerar que há diferenças teóricas substanciais conforme a perspectiva de estudo assumida. Para exemplificar, podemos citar a distância que há entre os estudos da Semântica Formal e da Semântica Argumentativa no que tange à abordagem da argumentação. Todas essas ramificações teóricas resultam num tratamento bastante plural da noção de argumentação e de outros aspectos da língua diretamente relacionados a esse assunto.

Embora seja importante que o professor de língua tenha uma noção geral dessas teorias, até para poder localizar seu trabalho dentro delas, não pretendemos apresentar neste artigo uma revisão teórica sobre as diferentes teorias e suas implicações para o ensino. Com base em nossa experiência na docência de Língua Portuguesa, tanto no ensino básico como na licenciatura e na formação continuada de professores, buscamos trazer algumas reflexões sobre a abordagem da argumentação a partir do que observamos ser recorrente tanto no discurso de professores em formação ou em exercício quanto nos materiais de apoio que chegam às escolas, especialmente o livro didático. Pontuamos algumas questões que achamos pertinentes para uma reflexão inicial do professor de Língua Portuguesa sobre o ensino de argumentação, muito embora compreendamos que o alcance dessa questão deva ultrapassar o domínio dessa disciplina, e mesmo das outras que figuram na área das Linguagens.

O tópico 'argumentação' constitui para nós um assunto caro não só por ser assunto central de nossas pesquisas, mas também porque consideramos ser esse um assunto pelo qual a escola não pode passar de maneira pontual, breve e pouco aprofundada. Tratase de uma questão que precisa constar como tópico de ensino em todas as séries do ensino básico na disciplina de Língua Portuguesa, quiçá em outras disciplinas, pelo menos naquelas que integram as Ciências Humanas.

Para exemplificar como esse tópico tem sido abordado no ensino de Língua Portuguesa e para fundamentar o debate a respeito dessa questão, recorremos a recortes de livros didáticos voltados 
para os ensinos Fundamental e Médio. Advertimos, contudo, que não pretendemos aqui apresentar uma pesquisa que considere o livro didático como um todo, pois a abordagem que propomos focaliza os capítulos que abordam explicitamente a 'argumentação'.

Organizamos o texto em três partes, além desta introdução e da conclusão. Na primeira parte, fazemos breves considerações sobre a argumentação segundo o paradigma clássico; na segunda parte, abordamos a noção de argumentação stricto sensu; e, na terceira parte, apresentamos reflexões sobre a argumentação lato sensu, que é o foco da discussão que propomos.

PARA COMEÇO DE CONVERSA: a argumentação segundo o paradigma clássico

Embora este texto não pretenda fazer uma revisão da literatura no que tange à argumentação vista a partir do paradigma clássico (ou tradicional), uma apresentação rápida dessa perspectiva contribui para os objetivos que motivaram a construção deste artigo, uma vez que esta pesquisa pretende somar-se a outras que buscam mostrar a necessidade de ultrapassar esse modelo quando se pensa em contextos de ensino atuais.

Segundo Breton (1999), o surgimento da argumentação como saber sistemático remonta ao século $V$ a.C., na região do Mediterrâneo. Perelman e Olbrechts-Tyteca (1996) vão mais longe na história e citam estudos sistemáticos sobre essa temática já no século $\mathrm{XV}$ a.C. Outros autores percorrem ainda outros caminhos históricos. Embora o princípio dos estudos sobre o tema não possa ser acessado com precisão, parece não haver discordância entre os teóricos quando o assunto é o papel fundamental de Aristóteles (Grécia, 384322 a.C.) na sistematização de conhecimentos a respeito dessa temática e sua contribuição para a construção do paradigma clássico.

Conforme Plantin (2008), a perspectiva clássica remonta aos estudos da Retórica, da Dialética e da Lógica. O autor apresenta um resumo da base do sistema no qual a argumentação foi pensada desde Aristóteles até o século XIX: "Do ponto de vista da organização clássica das disciplinas, a argumentação está vinculada à lógica, 'a 
arte de pensar corretamente', à retórica, 'a arte de bem falar', e à dialética, 'a arte de bem dialogar' ." (PLANTIN, 2008, p. 8-9).

O conceito de argumentação tomado por esse viés está relacionado à concepção de linguagem como expressão do pensamento, sendo os textos o lugar de realização da expressão lógica. Embora alguns componentes pragmáticos, como a imagem do interlocutor que se quer persuadir, chegam a ser considerados nessa perspectiva, esse conjunto de orientações segue essencialmente a lei da psicologia individual, sem considerar o caráter sociointerativo da linguagem, pois o que está em jogo é a própria estruturação linguística da argumentação em torno de um tema que gera debate.

Ademais, pontua-se a necessidade de seguir regras para a organização lógica do pensamento. Elas são traduzidas em encadeamento de proposições, pautadas na indexação referencial e em normas gramaticais que devem orientar a comunicação, especialmente no que tange à modalidade oral. $O$ uso da língua, nessa concepção, pode ser resumido à adequação a normas e a estruturas lógicas que, em tese, garantiriam uma elocução exitosa.

O paradigma clássico ainda tem presença forte no ensino de Língua Portuguesa, embora na atualidade se enfatize a modalidade escrita. Esse quadro deixa em relevo o longo percurso por que passaram as teorias da Retórica, da Dialética e da Lógica e a solidez dos fundamentos desses estudos, ainda que tenham passado por momentos de descrédito, ruptura e reconstrução, como ocorreu com a Retórica na virada do século XIX para o século XX (PLANTIN, 2008).

$\mathrm{Na}$ atualidade, o paradigma clássico é observado, por exemplo, em livros didáticos que limitam o tratamento da argumentação a gêneros textuais específicos em que ocorre o debate explícito, a contextos em que se emitem opiniões na tentativa de levar ao convencimento pela prova, apresentada com base no raciocínio lógico. Em geral, tal orientação prima pela estrutura da argumentação, por exemplo, explorando a tríade 'argumentos, premissas e conclusões', comumente analisada em frases deslocada de qualquer contexto real de interação, e apresentando os tipos de argumentos (de senso comum, por analogia, ab absurdo, per exclusionem, a posteriori, e assim por diante). Já reflexões acerca do 
valor argumentativo de marcas linguísticas postas em cena no texto dificilmente ganham espaço nesse tipo de abordagem, ainda que se focalizem textos argumentativos no sentido estrito, nos quais ficam mais evidentes as marcas linguísticas da argumentação. Também são desconsideradas as características pertinentes às situações de produção do texto.

Esse parece ser um quadro bastante comum no ensino de Língua Portuguesa, conforme apontado por alguns autores. Barbisan (2007), por exemplo, em estudo a respeito da abordagem da argumentação em livros didáticos, observa que a construção do sentido no uso da linguagem não é estudada. A autora ressalva que, de um total de quatro livros analisados, esse aspecto foi observado em apenas um deles; ainda assim, é apenas "rapidamente" abordado, para usar o termo empregado pela pesquisadora. Os livros analisados pela autora parecem bem representativos do material que ainda hoje tem chegado às escolas.

Leal e Morais (2006) também observam que matérias voltadas ao ensino da argumentação não enfatizam estratégias que os indivíduos adotam para satisfazer as condições do contexto de produção, mesmo porque tais condições sequer são pontuadas como objeto de análise.

Conforme dito acima, o paradigma clássico está calcado na noção de argumentação stricto sensu, tópico da próxima seção. A abordagem didática da argumentação no sentido estrito não necessariamente precisa perpassar por práticas tradicionais. Os gêneros que comportam de forma predominante as sequências argumentativas podem (e devem) ser explorados a partir de uma perspectiva mais atualizada em relação ao tratamento didático dos gêneros, dentro de uma de uma proposta de estudo da linguagem como atividade sociointerativa. No entanto, a própria recorrência dessa circunscrição em torno do sentido estrito pode ser considerada um indício da resistência do paradigma clássico. 
A CONVERSA CONTINUA: a noção de argumentação stricto sensu

A ideia de que a argumentação se dá em determinados contextos de interação em que há a expressa vontade do produtor do texto de fazer valer seu ponto de vista sobre um determinado assunto, buscando levar o interlocutor a se alinhar à perspectiva apresentada no texto está focada na noção da argumentação stricto sensu. Essa categoria, segundo Koch e Fávero (1987), enquadraria os textos tradicionalmente denominados argumentativos, ou seja, aqueles textos em que a argumentatividade é dada de forma explícita, atingindo seu grau máximo.

Leal et al. (2010) analisam discurso de professoras do ensino Fundamental e observam que, de modo geral, as entrevistadas associam o termo 'argumentação' a discussão ou a opinião. Em nossa experiência profissional, temos percebido que essa noção está presente no imaginário de grande parte dos professores de Língua Portuguesa, refletindo a noção estrita do termo.

O recorte abaixo, retirado de um livro didático do ensino Fundamental, da seção Produção de texto, sob o subtítulo Razões e conclusões na argumentação, é também bastante representativo da noção de argumentação que esse tipo de material tem seguido:

No dia-a-dia das pessoas, é comum haver divergências a respeito de determinados assuntos, como, por exemplo, qual é o melhor grupo de rock da atualidade, se certo programa de tevê é bom ou ruim, qual foi o melhor prefeito da cidade, se a atuação da polícia em seu bairro vem sendo eficiente ou não, etc. A cada vez que externamos nosso ponto de vista sobre esses assuntos e explicamos as razões de pensarmos assim, estamos argumentando [...]. Quando argumentamos, desejamos convencer o interlocutor sobre nosso ponto de vista. Para isso, não basta dizermos qual é nossa opinião, é preciso explicar por que pensamos assim, quais as razões dessa opinião (CEREJA; MAGALHÃES, 1998, p. 134, grifo dos autores). 
Segundo essa perspectiva, há contextos específicos e temas específicos que podem gerar argumentação. Essa perspectiva desconsidera a essência argumentativa da linguagem.

A abordagem desse tópico de ensino a partir do viés clássico é recorrente também em obras mais recentes. Exemplificamos com o recorte abaixo, retirado da obra Português: contexto, interlocução e sentido, na abertura de unidade de Produção de texto nominada Argumentação, texto que se repete nos três volumes da coleção:

\begin{abstract}
A argumentação vem sempre associada a um desafio: convencer alguém de alguma coisa, demonstrar a validade de uma tese, defender um ponto de vista. Cada uma dessas finalidades se manifestara, em maior ou menor grau, nos gêneros discursivos apresentados nesta unidade. Ao conhecê-los, saberemos melhor como selecionar e organizar argumentos de natureza diferente para alcançar objetivos como demonstrar, persuadir e convencer (ABAURRE; ABAURRE; PONTARA, 2013, p. 365).
\end{abstract}

A ideia de "convencer alguém de alguma coisa" pode ser aplicada em contextos em que não se recorre à argumentação stricto sensu. Podemos exemplificar essa análise com uma notícia sobre o Projeto de Lei que trata da reforma do Ensino Médio, a qual pode, por exemplo, direcionar o leitor à conclusão de que o projeto é salutar à Educação ou, em outra direção, à conclusão de que a proposta de reestruturação resultará em perdas para os estudantes e para sociedade de forma geral. E assim poderíamos seguir com outros muitos exemplos, envolvendo qualquer outro gênero. Mas, no recorte apresentado, a expressão em tela se apresenta atrelada a contextos específicos em que os interlocutores se reconhecem em uma interação em que aquele que fala/escreve assume a posição de alguém que defende um ponto de vista de maneira explícita e que quer convencer o outro de seu ponto de vista.

Ainda nessa perspectiva, podemos tomar de exemplo a coleção Ser protagonista: Língua Portuguesa (Edições SM), que, na mesma linha, define a argumentação em seu sentido estrito, intimamente ligado à definição clássica, como se observa nestes 
recortes, que abrem as unidades intituladas Argumentar, em dois de seus volumes:

A vida em sociedade exige dos seres humanos um posicionamento em relação ao mundo em que vivem. Isso envolve, cotidianamente, o uso da argumentação. A criança que deseja um brinquedo novo já procura formas de convencer seus pais, assim como o profissional que procura uma colocação no mercado de trabalho, a namorada que quer convencer o companheiro a viajar, etc. Usando o raciocínio lógico e articulando conhecimentos de diversas áreas do saber, o discurso argumentativo defende um ponto de vista, lançando mão de argumentos que procuram levar o interlocutor a concordar com a posição defendida (EDIÇÕES SM, 2013, p. 361, vol. 1).

Saber argumentar dá ao cidadão o poder de participar mais ativamente da sociedade. Os gêneros textuais orais e escritos baseados na argumentação permitem a seus produtores defender opiniões sobre assuntos socialmente relevantes. Para isso, é importante saber criar e reconhecer um ponto de vista, compreender e refutar argumentos em uma discussão e justificar posições com base em argumentos lógicos e valores sociais (EDIÇÕES SM, 2013, p. 351, vol. 2).

Vamos aqui aprofundar um pouco mais a discussão em torno da argumentação stricto sensu, pois esse entendimento é imprescindível para chegarmos à ideia de uma argumentação lato sensu, tão necessária como tópico de ensino quanto a stricto sensu, conforme defendemos neste artigo. O texto argumentativo em sentido estrito pode ser definido como um texto baseado em opinião no qual um falante ou escritor toma uma postura particular frente a um tema e tenta convencer o ouvinte ou leitor a adotar tal posição (GOLDER; COIRIER, 1996). Se enfocarmos os efeitos pretendidos, pode-se dizer que um texto argumentativo "deve ser admissível no sentido de que as razões que são apresentadas para apoiar um ponto de vista devem ser aceitas, ou pelo menos aceitável, para o 
destinatário" (GOLDER; PERCHERON; POUIT, 1999, p. 100, tradução nossa).

Quanto às características do texto argumentativo stricto sensu, recorre-se aqui às categorias propostas por Koch e Fávero (1987). Para as autoras, um texto dessa natureza pode ser reconhecido por certas características que se agrupam em três dimensões distintas, porém complementares:
a) dimensão pragmática:
macro-ato: convencer, persuadir
atitude comunicativa: fazer crer/fazer fazer
atualização em situações comunicativas: textos publicitários, propagandísticos, peças judiciárias, matérias opinativas etc.
b) dimensão esquemática global superestrutura argumentativa: ordenação ideológica dos argumentos e contra-argumentos. categorias: (tese anterior) premissas - argumentos - (contra-argumentos) - (síntese) - conclusão (nova tese)
c) dimensão linguística de superfície marcas: modalizadores, verbos introdutores de opinião, operadores argumentativos, metáforas temporais, recurso à autoridade etc. $(\mathrm{KOCH}$; FÁVERO, 1987, p. 7-8).

Quanto aos aspectos relativos à dimensão pragmática, o texto argumentativo stricto sensu envolve a vontade de convencer, de persuadir, que é explicitada e assumida pelo produtor do texto. A atitude comunicativa é, então, um aspecto que direciona não apenas a produção do texto, mas também a sua leitura, uma vez que produtor e leitor estão cientes dos efeitos perlocucionários que se espera alcançar por meio desse tipo de texto (CORBARI, 2013).

Corbari (2013) observa que essa dimensão envolve ainda muitos outros aspectos relevantes para a definição de um texto argumentativo stricto sensu. Uma delas diz respeito ao conteúdo abordado. Este, conforme Golder e Coirier (1994), deve provocar o debate, pois, "o falante deve perceber que o domínio argumentativo é controverso (só se argumenta sobre coisas que são discutíveis)" (GOLDER; COIRIER, 1994, p. 187, tradução nossa), o que significa dizer 
que, para ser discutível, o conteúdo abordado deve não apenas gerar debate, mas também ser acessível tanto para quem produz o texto quanto para o leitor/ouvinte previsto.

A discutibilidade do objeto de discurso é, segundo os autores, um dos pré-requisitos que governam a produção do texto argumentativo, que divide lugar com outro pré-requisito: "o falante deve querer apresentar o argumento por meio do discurso (e não por estratégias persuasivas como suborno ou ameaças)" (GOLDER; COIRIER, 1994, p. 187, tradução nossa). Ou seja, o produtor do texto argumentativo precisa estar de fato envolvido com o debate; deve não só ter algo a dizer, mas também querer dizê-lo. É só a partir dessas condições que se pode propor uma (re)construção do mundo extralinguístico em conformidade com a atitude comunicativa prevista: fazer crer/fazer fazer (KOCH; FÁVERO, 1987).

Quanto à segunda dimensão do texto argumentativo stricto sensu citada por Koch e Fávero (1987), a dimensão esquemática global, as autoras propõem que se observem as categorias tradicionalmente apresentada para o texto argumentativo, quais sejam: (tese anterior) premissas - argumentos - (contra-argumentos) - (síntese) - conclusão (nova tese). Trata-se de um esquema prototípico, que expõe passos necessários à estruturação de um texto argumentativo em sentido estrito.

Em outra direção, Golder (1996), Golder e Coirier (1994, 1996) e Golder, Percheron e Puit (1999) indicam a necessidade de o texto argumentativo não ser analisado em termos de etapas a serem seguidas. A proposta desses autores é a análise do texto conforme estratégias de justificação e negociação, considerando a situação de comunicação de que o texto emerge.

Em referência aos contextos de ensino de produção textual, Golder, Percheron e Puit (1999) assim justificam a recusa por analisar o texto argumentativo a partir de esquemas que explicitam passos a serem seguidos:

[...] não há uma boa maneira de argumentar; a natureza dos argumentos e a sua disposição não podem ser definidas de forma independente da situação em que o discurso será produzido, especialmente a posição do destinatário. Resta 
compreender o funcionamento da dupla enunciador-destinatário na construção de uma dissertação: quem é o destinatário? Como os alunos conseguem identificar as posições de seus destinatários sobre o tema em debate? (GOLDER; PERCHERON; POUIT, 1999, p. 108-109, tradução nossa).

Tomar essa orientação como guia na abordagem da argumentação stricto senso em sala de aula parece ser uma escolha pedagogicamente produtiva, uma vez que

[...] não engessa o texto argumentativo em etapa a cumprir, mas referenda a observação de estratégias linguístico-discursivas que colaboram para que [o texto] seja tomado pelo interlocutor como uma construção coerente, de onde emerge uma posição explicitada e ancorada por argumentos, numa dinâmica capaz de levar o interlocutor a tomar o texto como convincente, mesmo que não aceite as ideias postas no texto (CORBARI, 2013, p. 18).

Ademais, vale observar, conforme pontuam Leal e Morais (2006), que os protótipos de textos universais recorrentemente apresentados em materiais voltados para o ensino são idealizações, formulações em abstrato, que não correspondem a gêneros textuais reais: "Fala-se em 'textos argumentativos' como se existissem, nas práticas sociais, modelos únicos que satisfizessem às diferentes condições com as quais se deparam os indivíduos na sociedade" (LEAL; MORAIS, 2006, p. 19). O produtor de alguns gêneros, como o artigo de opinião, por se responsabilizar integralmente tanto em relação ao conteúdo que aborda quanto em relação às escolhas linguísticas que faz, pode desenvolver a argumentação sem seguir necessariamente o esquema prototípico da sequência argumentativa. Romper com a ideia de que precisamos seguir técnicas estruturais da argumentação quando nosso foco são os gêneros contemporâneos, e não aqueles sobre os quais se debruçava Aristóteles, significa ascender um degrau em direção a uma abordagem da língua como atividade sociointerativa. 
CHEGANDO AO PONTO: a noção de argumentação lato sensu

O debate que propomos neste texto está assentado na Semântica Argumentativa, que postula que a argumentatividade está inscrita na própria língua (DUCROT, 1987). Essa interpretação leva ao entendimento de que não há contextos e temas específicos que demandam a produção da argumentação, por esta ser intrínseca a qualquer uso que se faça da língua. Nesse sentido, não se pode conceber um texto livre da argumentação.

Koch $(2002$, 2003) contribui para essa discussão ao trazer questões que ultrapassam o limite do enunciado, pontuando a linguagem como uma forma de "ação sobre o mundo dotada de intencionalidade, vinculadora de ideologia, caracterizando-se, portanto, pela argumentatividade" $(\mathrm{KOCH}, 2002$, p. 15, grifo da autora). Nessa linha de análise, Koch $(2002,2003)$ postula que o ato linguístico fundamental é o ato de argumentar, uma vez que, na interação por meio da linguagem, o produtor orienta os enunciados que produz em direção a determinadas conclusões em detrimento de outras, dotando assim os enunciados de força argumentativa.

Ascombre e Ducrot (1976) assim explicam o sentido de "orientar argumentativamente": "[...] argumentar a favor de $C$ por meio de $\mathrm{A}$ (usando $\mathrm{A}$ em favor da conclusão $C$ ) é, para nós, 'apresentar $A$ como devendo levar o destinatário à conclusão $C^{\prime}$, 'dar A como uma razão para acreditar em C'" (ASCOMBRE; DUCROT, 1976, p. 13, tradução nossa).

Nessa concepção, o ato de 'argumentar' não está atrelado à arte da persuasão, mas ao encadeamento de proposições que conduz a uma conclusão. A orientação argumentativa é, então, uma característica constitutiva da linguagem: "[...] não podemos usá-los sem a pretensão de orientar o interlocutor em direção a certo tipo de conclusão (pelo fato que se exclui outro tipo de conclusão)" (ASCOMBRE; DUCROT, 1976, p. 13-14, tradução nossa). Nesse sentido, pode-se dizer, conforme as palavras de Lyons, que, "quando comunicamos alguma proposição para outra pessoa, o fazemos, geralmente, porque queremos influenciar de alguma maneira suas crenças, suas atitudes e seu comportamento" (LYONS, 1977, p. 725, tradução nossa). 
Vale ressalvar que essa noção é essencial para a defesa da deia de que não há texto livre de argumentação, mas é preciso observar que, na teoria ducrotiana, a argumentação é reconstruída em um plano exclusivamente linguístico, de acordo com o programa estruturalista da linguística (PLANTIN, 2008). Além de não estar interessada diretamente na noção sócio-histórica da linguagem, essa teoria não foi pensada para contextos de ensino. No entanto, a compreensão da teoria apresentada por Ducrot e seus colaboradores permite que se pense na argumentação para além dos esquemas lógico-semânticos e estruturais que ainda centralizam a discussão quando do ensino desse tópico. Trata-se de uma perspectiva que permite uma ruptura com o modelo clássico, passando da técnica especializada de planejamento lógico-discursivo para a argumentação inerente à linguagem.

Outro teórico mais recorrentemente acessado pelos professores de língua que contribui para a ideia de argumentação como ato intrínseco às interações por meio da linguagem é Bakhtin, embora o filósofo não tenha apresentado de forma explícita essa relação em seus escritos, conforme observa Goulart (2007). A autora pontua aspectos da teoria bakhtiniana que sustentam a ideia de que enunciar é argumentar:

(1) A argumentatividade da linguagem é inerente ao princípio dialógico, já que todo enunciado é produzido intencionalmente na direção do Outro, no movimento da interminável cadeia de enunciações. (2) Enunciar é agir sobre o Outro, isto é, enunciar extrapola a idéia de compreender e responder enunciados (GOULART, 2007, p. 94).

Para Bakhtin (2002, 2003), a linguagem é essencialmente dialógica. A palavra deve ser tomada como signo ideológico por excelência, e a estrutura da enunciação é determinada pela situação social mais imediata e o meio social mais amplo (BAKHTIN, 2002). Ao considerar que "a enunciação é o produto da interação de dois indivíduos socialmente organizados" (BAKHTIN, 2002, p. 112), o filósofo destaca a natureza social da linguagem, levando ao entendimento de que não há uso da língua sem que seja 
ideologicamente orientado e intencionalmente motivando. Para o autor, o enunciado sempre carrega julgamentos de valor social, um tom apreciativo, o que pressupõe 0 uso inerentemente argumentativo da linguagem.

Ademais, vale observar o destaque dado à figura do interlocutor na perspectiva bakhtiniana, ao considerar que a palavra sempre proceder de alguém e se dirigir a alguém: "A palavra dirigese a um interlocutor: ela é função da pessoa desse interlocutor" (BAKHTIN, 2002, p. 112) e variará conforme for esse interlocutor. Em outros termos, "desde o início [...] o enunciado se constrói levando em conta as atitudes responsivas, em prol das quais ele, em essência, é criado". [...]. É como se todo o enunciado se construísse ao encontro dessa resposta" (BAKHTIN, 2003, p. 301).

O texto é emoldurado, tanto em termos do conteúdo expresso quanto em relação às formas escolhidas para fazê-lo, considerando o interlocutor e seu papel ativo na interação dada pela língua. Nesse sentido, as escolhas do conteúdo enunciado, do gênero escolhido para expressá-lo e a forma linguística de sua realização estão sempre empenhadas na figura do interlocutor. Assim, todo enunciado é intencionalmente modulado conforme as intenções do locutor e considerando as condições de produção em que está inserido e ao interlocutor a que se dirige.

Em termos linguísticos, a orientação argumentativa pode ser atualizada no texto de forma mais ou menos explícita, a depender do projeto de dizer envolvido em cada situação comunicativa. Conforme explicam Koch e Fávero (1987), num continuum argumentativo, podem-se localizar textos dotados de maior ou menor argumentatividade.

Alguns livros didáticos - poucos, infelizmente - já estão pelo menos pincelando essas questões quando abordam a argumentação como tópico de ensino. Exemplifica esse avanço no tratamento pedagógico do tema o recorte abaixo, retirado de capítulo que trata de Persuasão e argumentação. Depois de apresentar uma citação do linguista Hjelmslev sobre a linguagem como instrumento graças ao qual o homem, entre outras coisas, influencia e é influenciado, como a base mais profunda da sociedade humana, os autores apresentam a seguinte análise: 
De fato, é pela linguagem que o homem se realiza socialmente, expressando o que pensa e sente e ouvindo o que os outros pensam e sentem. Daí falarmos em interação social, ou seja, por meio dos textos (verbais ou não-verbais) que constrói, há sempre alguém tentando agir sobre outra pessoa e vice-versa. [...] (TERRA; NICOLA, 2008, p. 93).

Embora, na sequência, o mesmo livro didático acabe voltando à noção clássica de argumentação, apresentando-a como uma "estrutura criada de forma deliberada e que pressupõe o uso de estratégias lingüísticas e racionais" (TERRA; NICOLA, 2008, p. 93), mais à frente encontra-se um capítulo em que se fala em Objetividade $e$ subjetividade no texto argumentativo, sob o subtítulo Todo texto manifesta uma opinião. Nesse ponto, os autores recorrem à fala de Arbex (1999 apud TERRA; NICOLA, 2008, p. 142) sobre o jornalismo da década de 90:

Claro que tudo isso [a objetividade no jornalismo] é um grande engano. Não há e nunca houve, de fato, nenhum jornalismo 'objetivo' e 'sem opinião': todo texto - jornalístico ou não - manifestam uma opinião. Até mesmo a demonstração de uma fórmula ou teorema matemático, aliás, não é feita da mesma forma por dois expositores. Os caminhos escolhidos para chegar ao mesmo ponto revelam a diferença de estilo, revelam o autor.

$\mathrm{E}$, na sequência, sob o subtítulo $O$ mito da impessoalidade, apresentam a seguinte explicação, contexto em que recorrem às palavras de Orlandi :

Nesse ponto, é preciso reforçar uma idéia: a língua materializa o discurso, que, por sua vez, é a materialização da ideologia. Temos assim uma relação fundamental: ideologia $\rightarrow$ discurso $\rightarrow$ linguagem. E, como nos ensina Eni Orlandi, "não há discurso sem sujeito e não há sujeito sem ideologia". Por isso, quanto lemos um texto, não podemos nos prender apenas às evidências, àquilo que está visível, que se mostra claramente. Por trás das aparências, há sempre alguém escrevendo com 
determinadas intenções, segundo seus valores, seu modo de ler e interpretar o mundo (TERRA; NICOLA, 2008, p. 143).

Embora os autores focalizem questões relativas ao texto argumentativo stricto sensu, os recortes do livro que apresentamos nesta seção mostram que se preocuparam em partir de uma noção de argumentação mais ampla. São esforços nesse sentido que defendemos neste trabalho. Entendemos que promover a noção de argumentação lato sensu a tópico de ensino, partindo de um tratamento planejado e sistematizado, é imprescindível para que o aluno consiga compreender a natureza sociointerativa da linguagem e a língua como portadora de ideologias.

Essa abordagem é cara à formação de usuários da língua que tenham clareza de que não há texto neutro, objetivo, imparcial $(\mathrm{KOCH}, 2003)$, e de que os índices de subjetividade introjetados no discurso podem variar, de maneira que pode ser mais fácil ou mais difícil captar sua orientação argumentativa. Sem esse trabalho com a noção de argumentação intrínseca à língua fica difícil garantir ao aluno a compreensão de que
A pretensa neutralidade de alguns discursos (o científico, o didático, entre outros) é apenas uma máscara, uma forma de representação (teatral): o locutor se representa no texto "como se" fosse neutro, "como se" não estivesse engajado, comprometido, "como se" não estivesse tentando orientar o outro para determinadas conclusões, no sentido de obter dele determinados comportamentos e reações $(\mathrm{KOCH}, 2003$, p. 60).

O caminho metodológico proposto na obra de Terra e Nicola (2008) é imprescindível para a formação de cidadãos que consigam, de fato, interpretar textos, posicionar-se criticamente e compreender a realidade que os cerca. Embora a abordagem proposta pelos autores não tenha a profundidade que consideramos que o tema mereça, apresenta-se como um grande avanço em relação às abordagens feitas na maioria dos livros didáticos que já consultamos ou analisamos, como exemplificam os recortes citados na seção anterior. 
Possibilitar ao estudante reflexões sobre a natureza argumentativa da linguagem é um primeiro passo necessário para um trabalho mais crítico dos discursos que os cercam. O tratamento da argumentação em sentido lato embasa, por exemplo, a discussão do mito da impessoalidade feita pelos autores no livro didático citado nesta seção. Terra e Nicola (2008) exploram questões de argumentação na notícia jornalística ou outros gêneros ditos 'imparciais', reflexão que dificilmente seria promovida por uma obra pautada no paradigma clássico e na noção estrita da argumentação.

$E$, mais, entendemos que a ideia de que enunciar é argumentar deve permear todo o ensino básico, não apenas o Ensino Médio. É possível adequar a linguagem para alcançar alunos desde a fase de alfabetização. Quanto mais consciência o aluno tiver sobre a natureza social, dialógica e ideológica da linguagem, e, mais especificamente, sobre a natureza argumentativa da língua, melhores condições terá de assumir-se como um cidadão crítico, capaz de interpretar não só textos e discursos, mas também as complexas relações sociais de que participa.

\section{CONSIDERAÇÕES FINAIS}

Considerando o pressuposto de que o projeto de dizer integra a atividade verbal $(\mathrm{KOCH}, 2003)$, resultando em ações linguísticas propriamente ditas, entendemos que não é possível visualizar uma linha capaz de delimitar o locus da argumentação, pelo menos quando tomada lato sensu, em relação aos usos que se faz da linguagem, uma vez que tais usos e a argumentação constituem atividades linguísticas que são, em essência, imbricadas.

Este trabalho está guiado pelo objetivo de trazer reflexões sobre a necessidade de ampliarmos a noção de argumentação trabalhada em sala de aula. Não se está aqui desconsiderando a relevância do trabalho com a perspectiva estrita do termo. Ao contrário, entendemos que trabalhar a sequência argumentativa mostrando ao aluno como ela se realiza em diferentes gêneros orais e escritos é imprescindível para a formação do leitor, do produtor do texto e do cidadão que almejamos. Mas consideramos que essa abordagem não é suficiente. 
Precisamos observar a escola como um locus da argumentação, porque aí se dão processos de interação social. Conforme observa Goulart (2010), a argumentação pode ser pensada nos movimentos intencionais da aula, por exemplo, por meio da flexibilização das palavras de autoridade das inter-relações de enunciados, da intersubjetividade, manifestando-se no discurso pelo tom apreciativo, pelos tempos-espaços agenciados e, especialmente, pelo entranhamento de palavras alheias nos enunciados, como palavras citadas, entre outras possibilidades. Só a análise das interações que se dão no espaço escolar já renderia muito trabalho baseado na perspectiva da argumentação lato sensu. Mas essa é uma questão a ser discutida em outro estudo. Aqui, envidamos esforços para argumentar em direção à necessidade de se pautar a argumentação lato sensu como tópico de ensino em todo o ensino básico, considerando o ato de argumentar como algo essencial a todo e qualquer discurso.

Essa abordagem contribuiria para chegarmos mais perto da teoria que aponta a linguagem como uma atividade sociointerativa, teoria que está há algumas décadas orientando teoricamente o ensino de línguas. Para tanto, precisamos superar o paradigma clássico, não o desconsiderando como contributo para discutir questões de argumentação stricto sensu, mas entendendo-o como uma contribuição que precisa ser ponderada no trabalho com os gêneros da atualidade.

Em interação com livros didáticos, temos observado que, em geral, pelo menos na última década, eles têm seguido três encaminhamentos metodológicos quando do ensino da 'argumentação', que descrevemos a seguir. Ressalvamos que tal constatação não pode ser tomada como uma comprovação científica, pois carece de um estudo sistemático, o que será feito em momento posterior à publicação deste texto; ainda assim, apresento-a por entender a validade de observações empíricas quando se tem em mente o ensino:

i) Apresentam o conteúdo a partir da estruturação da ordem do dissertar. Esse encaminhamento está presente inclusive nas obras mais atuais, como é o 
caso da coleção do Ensino Médio Novas Palavras (AMARAL et al., 2013). Nesses casos, a abordagem proposta tende a não conceituar 'argumentação', a ter como norte o paradigma clássico, a enfocar a noção estrita de argumentação e a dar pouco ou nenhum espaço para o trabalho com os gêneros. A coleção citada inclusive descreve a 'dissertação argumentativa' como gênero, perspectiva que pode ser questionada, haja vista a possibilidade de se recorrer à sequência dissertativo-argumentativa em diferentes gêneros;

ii) Apresentam o conteúdo a partir da noção de gêneros que envolvem a argumentação stricto sensu sem fazer uma introdução explicativa sobre a noção de argumentação, como é o caso, por exemplo, da coleção Português: linguagens em conexão (SETTE; TRAVALHA; BARROS, 2013). Essa perspectiva está mais de acordo com estudos sobre a linguagem presentes em discussões acadêmicas e nos documentos oficiais que orientam o ensino da língua, mas também não considera a noção de argumentação lato sensu;

iii) Apresentam uma definição de 'argumentação', ainda que de forma indireta, geralmente em uma página introdutória, para depois propor um trabalho sobre alguns gêneros que estão pautados na argumentação stricto sensu, como ocorre nas obras citadas neste artigo. Esse percurso didático possibilita a abordagem da argumentação tanto no seu sentido estrito, como o fazem Abaurre, Abaurre e Pontara (2013), por exemplo, quanto no sentido lato, como se verifica em Terra e Nicola (2008).

Entendemos que essa terceira forma de abordar o conteúdo é mais adequada, justamente porque abre espaço para se falar na argumentação lato sensu, mesmo tendo como foco de atenção da unidade a argumentação stricto sensu. Embora a abordagem da 
argumentação lato sensu, na perspectiva que defendemos aqui, deva perpassar todo o ensino da Língua Portuguesa, uma vez que não se considera a existência de texto livre de argumentação, entendemos que é necessário pontuar em que momento do currículo esse tema passará por um estudo sistematizado, como ocorre com a argumentação em sentido estrito.

Esse trabalho sobre a natureza argumentativa da linguagem parece ser um caminho produtivo inclusive para o ensino da argumentação em sentido estrito, uma vez que, ao tomar consciência do que podemos fazer com a linguagem e da ideia de que não há interação livre de intenções, traça-se uma ponte que contribui para que o aluno consiga passar do nível pré-argumentativo para um estágio elementar de argumentação e, após, para uma argumentação elaborada (GOLDER; COIRIER, 1994). Entender a essência social e interativa da atividade linguageira é imprescindível para se chegar a uma estruturação textual própria em que predominam sequências argumentativas.

Trabalhar de forma organizada e programada a noção de argumentação latu sensu implica em uma postura política. E nos parece cada vez mais urgente que tais questões sejam abordadas, considerando que disciplinas como Sociologia e Filosofia, que orientam um olhar mais crítico para o mundo e mais reflexivo para o lugar que cada um ocupa no círculo social, tendem, com a Reforma do Ensino Médio, a serem cada vez mais suprimidas dos currículos.

Em resumo, argumentamos pela necessidade de se considerar a escola como um locus da argumentação, não apenas por ela comportar, em si, um contexto social vivo, espaço em que se interage por meio da linguagem e, portanto, se argumenta, mas principalmente por ser o lugar do ensino formal e talvez um dos poucos contextos, se não o único, em que o aluno terá possibilidade de ter contato com um trabalho sistematizado e planejado sobre a linguagem, a língua e a relação enunciação $x$ argumentação. E a disciplina de Língua Portuguesa é o lugar por excelência em que essa abordagem precisa ser feita, muito embora as discussões sobre a argumentação lato sensu possam e devam ser feitas em qualquer disciplina. Afinal, a própria escolha das disciplinas que participam da 
grade escolar e dos conteúdos que figuram no currículo de cada disciplina passam por escolhas, ou seja, pela argumentação.

\section{REFERÊNCIAS}

ABAURRE, Maria Luiza M.; ABAURRE, Maria Bernadete M.; PONTARA, Marcela. Português: contexto, interlocução e sentido. 2. ed. São Paulo: Moderna, 2013. vol . 1, 2 e 3.

AMARAL, Emília et al. Novas palavras. 2. ed. São Paulo: FTD, 2013. vol. 1,2 e 3 .

ASCOMBRE, Jean-Claude; DUCROT, Oswald. L'argumentation dans la langue. Langages, 10e année, n. 42, p. 5-27, 1976.

BAKHTIN, Mikhail. Os gêneros do discurso. In: BAKHTIN, Mikhail. Estética da criação verbal. Trad. Paulo Bezerra. 4. ed. São Paulo: Martins Fontes, 2003. p. 261-306.

BAKHTIN, Mikhail [N. V. Volochinov]. Marxismo e filosofia da linguagem. Trad. Michel Lahud e Yara Frateschi Vieira. 10. ed. São Paulo: Annablume; Hucitec, 2002.

BARBISAN, Leci Borges. Uma proposta para o ensino da argumentação. Letras de hoje, Porto Alegre, v. 42, n. 2, p. 111-138, jun. 2007. Disponível em:

http://revistaseletronicas.pucrs.br/ojs/index.php/fale/article/view/24 15. Acesso em: 25 abr. 2010.

BRETON, Philippe. A argumentação na comunicação. Trad. Viviane Ribeiro. Bauru: EDUSC, 1999.

CEREJA, William Roberto; MAGALHÃES, Thereza Cochar. Português: linguagens: $8^{a}$ série. São Paulo: Atual, 1998.

CORBARI, Alcione Tereza. Elementos modalizadores como estratégia de negociação em textos opinativos produzidos por alunos de Ensino Médio. 2013. 220f. Tese (Doutorado em Letras e Linguística) - Programa de Pós-Graduação em Letras e Linguística, Universidade Federal da Bahia, Salvador, 2013. 
DUCROT, Oswlad. O dizer e o dito. Trad. Eduardo Guimarães. Campinas: Pontes, 1987.

EDIÇÕES SM. Ser protagonista: Língua Portuguesa, $1^{\circ}$ ano - ensino médio. Editor responsável: Rogério de Araújo Ramos. 2. ed. São Paulo: Edições SM, 2013. (Coleção Ser protagonista, vol. 1 e 2).

GOLDER, Caroline. La production de discours argumentatifs: revue de questions. Revue française de pédagogie, Paris, v. 116, p. 119134, 1996.

GOLDER, Caroline; COIRIER, Pierre. The production and recognition of typological argumentative text markers. Argumentation, Dordrecht-Boston, v. 10, p. 271-282, 1996.

GOLDER, Caroline; COIRIER, Pierre. Argumentative text writing: developmental trends. Discourse Processes, Philadelphia, v. 18, p. 187-210, 1994.

GOLDER, Caroline; PERCHERON, Aurélie; POUIT, Delphine. Les choses ne sont jamais totalement vraies ou totalement fausses: point de vue sur la conduite communicative d'argumentation en production écrite. Enfance, Paris, t. 52, n. 2, p. 99-110, 1999.

GOULART, Cecília. Processos escolares de ensino e aprendizagem, argumentação e linguagens sociais. Bakhtiniana, São Paulo, v. 1, n. 4, p. 50-62, 2 sem. 2010. Disponível em:

http://revistas.pucsp.br/index.php/bakhtiniana/article/viewFile/4298/ 2902. Acesso em: 19 fev. 2017.

GOULART, Cecília. Enunciar é argumentar: analisando um episódio de uma aula de História com base em Bakhtin. Pro-posições, v. 18, n. 3(54), p. 93-107, set./dez. 2007. Disponível em:

http://www.proposicoes.fe.unicamp.br/proposicoes/textos/54dossie-goulartc.pdf. Acesso em: 15 fev. 2017.

$\mathrm{KOCH}$, Ingedore Grunfeld Villaça. A inter-ação pela linguagem. 8. ed. rev. e ampl. São Paulo: Contexto, 2003.

$\mathrm{KOCH}$, Ingedore Grunfeld Villaça. Argumentação e linguagem. 8. ed. São Paulo: Cortez, 2002. 
KOCH, Ingedore Grunfeld Villaça; FÁVERO, Leonor. Contribuição a uma tipologia textual. Letras \& Letras, v. 3, n. 1, p. 3-10, 1987.

LEAL, Telma Ferraz et al. Entrevistando professoras: o que elas falam sobre o ensino da argumentação? Educação Unisinos, v. 14, n. 3, p. 195-204, set./dez. 2010. Disponível em:

http://www.revistas.unisinos.br/index.php/educacao/article/viewFile/ 699/126. Acesso em: 20 mar. 2017.

LEAL, Telma Ferraz; MORAIS, Artur Gomes. A argumentação em textos escritos: a criança e a escola. Belo Horizonte: Autêntica, 2006.

LYONS, John. Semantics. Cambridge: Cambridge University Press, 1977. v. 2.

PERELMAN, Chäim; OLBRECHTS-TYTECA, Lucie. Tratado da argumentação: a nova retórica. Trad. Maria E. G. G. Pereira. São Paulo: Martins Fontes, 1996.

PLANTIN, Christian. A argumentação. Trad. Marcos Marcionilo. São Paulo: Parábola Editorial, 2008. (Coleção Na ponta da língua; 21).

SETTE, Maria das Graças Leão; TRAVALHA, Márcia Antônia; BARROS, Maria do Rozário Starling de. Português: linguagem e conexão. São Paulo: Leya, 2013. vol. 1, 2 e 3.

TERRA, Ernani; NICOLA, José de. Português: de olho no mundo do trabalho: volume único para o ensino médio. 2. ed. São Paulo:

Scipione, 2008.

Submetido em: Fevereiro/ 2020.

Aceito em: Dezembro/ 2020. 